\title{
Patients' knowledge of heart failure and their perception of the disease
}

This article was published in the following Dove Press journal:

Patient Preference and Adherence

24 August 2017

Number of times this article has been viewed

\author{
Anna Płotka' \\ Edyta Prokop ${ }^{2}$ \\ Jacek Migaj ${ }^{2}$ \\ Ewa Straburzyńska-Migaj² \\ Stefan Grajek ${ }^{2}$ \\ 'Medical Faculty I, Poznań University \\ of Medical Sciences, Poznań, Poland, \\ ${ }_{2}^{2}$ st Department of Cardiology, \\ University Hospital of Lord's \\ Transfiguration, Poznań University of \\ Medical Sciences, Poznań, Poland
}

Purpose: The aim of this study was to gain a deeper insight into patients' perception of chronic heart failure (CHF) symptoms by analyzing their compliance with nonpharmacological recommendations.

Patients and methods: This was a prospective, single-center survey-based registry. Patients included in this study were hospitalized between December 2014 and January 2016 at the $1^{\text {st }}$ Department of Cardiology, University Hospital of Lord's Transfiguration, Poznań University of Medical Sciences, and had been diagnosed with CHF at least 3 months prior to inclusion. Participants were divided according to New York Heart Association (NYHA) functional class into mild CHF (NYHA I and II) and severe CHF (NYHA III and IV), and according to age into young ( $<50$ years), middle-aged ( $50-70$ years) and old ( $>70$ years). The survey included information about the patients' sex, age, education, length of the illness and 12 questions about their perception of CHF. This study included 201 patients. The mean age was $58 \pm 15$ years.

Results: The younger the patients, the more often they thought that CHF is curable. The patients presenting with severe CHF tended to think that CHF is incurable significantly more often than those with mild CHF. Most of the patients considered loss of appetite, cough and vomiting the least alarming symptoms. Significantly more patients with severe CHF exercised less and reported reduced sexual activity more often in comparison to the mild CHF patients. Most of the young patients reported no changes to their sexual activity, body mass index (BMI) or exercise after diagnosis of CHF. Most of the old patients exercised less than before diagnosis of CHF. Significantly more middle-aged patients reduced their BMI, quit smoking and reported lower sexual activity after diagnosis of CHF in comparison to the other groups.

Conclusion: Patients need to be better educated about the nature of CHF and the importance of lifestyle changes.

Keywords: chronic heart failure, patient knowledge, patient compliance, lifestyle changes, nonpharmacological recommendations

\section{Introduction}

Cardiovascular diseases (CVDs) are the major cause of death globally. More people die annually from CVDs than from any other cause. ${ }^{1}$ Overall, it appears that chronic heart failure (CHF) affects $1 \%-3 \%$ of the general population and $\sim 10 \%$ of the very elderly. ${ }^{2}$ The lifetime risk of developing heart failure (CHF) is one in five. ${ }^{3}$ In the developed countries, the number of patients with CHF is increasing. This trend is a result of an increasing number of the elderly and the survival improvement after acute myocardial infarction. ${ }^{4}$ Although $\mathrm{CHF}$ is an important epidemiologic problem, the awareness of most of its aspects in the general population in Europe is low. There are clear misconceptions for the nature, severity, treatment options and costs. ${ }^{5}$ In addition, the majority of studies reveal lack of knowledge of CHF among patients. ${ }^{6-8}$
Correspondence: Anna Płotka

Ist Department of Cardiology, University Hospital of Lord's Transfiguration,

Poznań University of Medical Sciences,

Osiedle Lecha 15/59, 6I-293 Poznań,

Poland

Tel +48 73 4I3 7/ 27

Fax +48618529472

Email anna.biskupska@poczta.onet.pl 
Moreover, old and very old patients with $\mathrm{CHF}$ often do not perceive it as a life-limiting disease. ${ }^{9}$ Recent studies highlight that the patients' ability to recognize and interpret $\mathrm{CHF}$ symptoms is limited. ${ }^{10}$ Furthermore, researchers reveal low compliance rate in following nonpharmacological regimen. ${ }^{7}$ The successful management of CHF includes substantial changes in patients' everyday life, including maintaining euvolemia, smoking and alcohol cessation, proper diet and exercise training. ${ }^{11} \mathrm{CHF}$ patient self-care is thought to be cardioprotective and complementary to optimal medical management in improvement of outcomes. ${ }^{12}$ However, many patients have problems with following nonpharmacological recommendations. ${ }^{7,13}$ Nonconcordance with treatment regimen may increase the risk for readmissions, longer hospitalization and worsening of symptoms. ${ }^{14}$ The aim of our article is to analyze CHF patients' compliance with nonpharmacological recommendations and to gain a deeper insight into their knowledge of CHF symptoms.

\section{Materials and methods}

This was a prospective, single-center survey-based registry. The survey was designed to include information about the patients' sex, age, education, length of the illness and 12 questions about their perception of the disease. The CHF symptoms, symptoms the patients consider alarming, the effect of treatment, how patients follow pharmacological and nonpharmacological recommendations and the influence of the disease on the patients' relationships were particularly explored. The subjects were divided according to New York Heart Association (NYHA) functional class into mild CHF (NYHA I and II) and severe CHF (NYHA III and IV), and according to age into young $(<50)$, middle-aged $(50-70)$ and old $(>70)$.

\section{Inclusion criteria}

This study included consecutive patients hospitalized between December 2014 and January 2016 at the 1st Department of Cardiology at University Hospital of Lord's Transfiguration of Poznań University of Medical Sciences with CHF diagnosed at least 3 months prior to inclusion, both symptomatic and asymptomatic (NYHA functional class I-IV), who were hospitalized because of exacerbation of $\mathrm{CHF}$, qualification for invasive treatment (implantable cardioverter defibrillator/ cardiac resynchronization therapy device implantation or heart transplantation) and for treatment or diagnostics of ischemic heart disease. Written consent was obtained before each interview. The study was approved by the Poznan' University of Medical Sciences Bioethical Committee.

\section{Statistical analysis}

Statistical analysis was performed using STATISTICA 12 Statsoft. Probability distribution of continuous variables was tested with Lillefors and Shapiro-Wilk tests. Student's $t$-test and analysis of variance (ANOVA) were used to compare continuous variables with normal distribution and Mann-Whitney $U$ and Kruskal-Wallis ANOVA tests were used for continuous variables with non-normal distribution. Chi-square tests were used for categorical variables. The data are expressed as mean values with standard deviation for continuous variables and percentages for categorical variables. A $P$-value of $<0.05$ was considered statistically significant for all the tests.

\section{Survey}

The survey was designed to include information about patients' sex, age and education, length of the illness and 12 questions about their perception of the disease.

1. The patients were asked to choose any number of the following items that they consider the most inconvenient: dependence on others, exercise intolerance, difficulties in performing daily activities, systematic drug intake, frequent hospitalizations and systematic follow-up medical visits.

2. The patients were asked to choose any number of the following symptoms that they consider the worst: dyspnea, nocturnal dyspnea, cough, chest pain, syncope, palpitations, edema, loss of appetite, orthopnea, vomiting, insomnia and tachycardia.

3. The patients were asked whether the pharmacological treatment relieved the symptoms.

4. The patients were asked to choose any number of the symptoms mentioned in question 2 that improved on the employed treatment.

5. The patients were asked to choose any of the symptoms mentioned in question 2 they consider alarming.

6. The patients were asked "Do you think CHF is curable?".

7. The patients were asked about their compliance with pharmacological recommendations suggested by cardiologist.

8. The patients were asked about their compliance with pharmacological recommendations suggested by GP or other specialist.

9. The patients were asked, according to their responses to 7 th and 8th questions, the reason for their noncompliance with pharmacological recommendations.

10. The patients were asked how the diagnosis of CHF influenced their lifestyle: diet change, exercise, body 
mass index (BMI) change, alcohol consumption, smoking and sexual activity.

11. The patients were asked how diagnosing CHF influenced their relationships with family.

12. The patients were asked how the diagnosing of $\mathrm{CHF}$ influenced their relationships with friends.

\section{Results}

\section{Baseline characteristics}

In total, 201 patients were included in this study. The mean age was $58 \pm 15$ years $(\min 20, \max 92)$. Most of them were men $(n=152,76 \%)$. Assessment at admission indicated that 67 patients had mild CHF (NYHA I and II) and 126 severe CHF (NYHA III and IV) (Table 1). There were no significant differences in age, sex and length of disease between the mild and severe CHF patients. The latter had significantly higher B-type natriuretic peptide (BNP) and N-terminal of the prohormone brain natriuretic peptide (pro-BNP) blood concentration (Table 2 ). There were 52 young (aged $<50$ years), 11 middle-aged (aged 50-70 years) and 37 old (aged $>70$ years) patients. These groups did not show any significant differences concerning severity of CHF symptoms (Table 3).

\section{Knowledge of $\mathrm{CHF}$}

Most patients with mild CHF believed their disease to be curable, and almost half of the severe CHF patients thought $\mathrm{CHF}$ to be incurable (Figure 1). The younger the patients, the more often they thought CHF to be curable, and most of the old patients claimed $\mathrm{CHF}$ incurable (Figure 2). The patients presenting with severe $\mathrm{CHF}$ tended to think $\mathrm{CHF}$ to be incurable significantly more often than those with mild CHF (Figure 1).

\section{Perception of symptoms of CHF}

Most of the patients with mild CHF considered chest pain, palpitations and dyspnea alarming. Among the patients with

Table I Baseline characteristics of study population $(\mathrm{N}=20 \mathrm{I})$

\begin{tabular}{ll}
\hline Characteristics & \\
\hline Age (years), mean \pm SD & $58 \pm 15$ \\
Male sex, $\mathrm{n}(\%)$ & $152(76 \%)$ \\
Length of disease (years), mean \pm SD & $12 \pm \mathrm{II}$ \\
NYHA functional class & \\
I-II, $\mathrm{n}(\%)$ & $67(33 \%)$ \\
III-IV, $\mathrm{n}(\%)$ & $126(63 \%)$ \\
BNP $(\mathrm{pg} / \mathrm{mL})$ & 667 \\
Pro-BNP $(\mathrm{pg} / \mathrm{mL})$ & 3,294 \\
\hline
\end{tabular}

Abbreviations: BNP, B-type natriuretic peptide; NYHA, New York Heart Association; pro-BNP, N-terminal of the prohormone brain natriuretic peptide.
Table 2 Characteristics by NYHA FC groups

\begin{tabular}{llll}
\hline Characteristics & $\begin{array}{l}\text { NYHA } \\
\text { FC I-II }\end{array}$ & $\begin{array}{l}\text { NYHA } \\
\text { FC III-IV }\end{array}$ & P-value \\
\hline Patients (n) & 67 & 126 & \\
Age (years), mean \pm SD & $56 \pm 14$ & $59 \pm 15$ & 0.14 \\
Male sex, n (\%) & $54(81 \%)$ & $90(71 \%)$ & 0.22 \\
Length of disease (years), mean \pm SD & $11 \pm I I$ & $12 \pm 12$ & 0.68 \\
BNP (pg/mL) & 405 & 821 & 0.002 \\
Pro-BNP (pg/mL) & 2,061 & 3,991 & 0.01 \\
\hline
\end{tabular}

Abbreviations: BNP, B-type natriuretic peptide; FC, functional class; NYHA, New York Heart Association; pro-BNP, N-terminal of the prohormone brain natriuretic peptide.

severe CHF, the most often chosen alarming symptoms were dyspnea, chest pain and palpitations. Significantly fewer patients in both groups chose loss of appetite, insomnia, vomiting and cough (Figure 3). The patients with mild CHF tended to choose palpitations as an alarming symptom significantly more often than those with severe CHF (Figure 3). Most of the young and middle-aged patients considered chest pain and dyspnea alarming (Table 4). The old patients considered tachycardia and dyspnea the most alarming. The least often chosen symptoms in all the groups were loss of appetite, cough and vomiting (Figure 4).

\section{Lifestyle changes}

Most of the mild CHF patients reported reducing alcohol consumption and BMI decrease. About one third of them quit smoking, changed their diet and exercised regularly. Among the severe CHF patients, more than half reported less exercise, more than one third quit smoking, changed their diet and reduced BMI and alcohol consumption. In both groups, the patients reported significantly lower sexual activity (Table 5). Significantly more patients with mild CHF exercised regularly compared to the severe CHF patients. Significantly more patients with severe CHF exercised less compared to those with mild CHF. Significantly more patients with severe CHF reported reduced sexual activity in comparison to the patients with mild CHF (Figure 5). Most of the young patients reported no changes to their sexual activity, BMI or exercise. Most of the middle-aged patients reported lower sexual activity, quitting smoking and reducing their BMI. Most of the old patients reported no changes to their sexual activity and BMI, but they exercised less (Table 5). Significantly more middle-aged patients reduced their BMI, quit smoking and reported lower sexual activity in comparison to the other groups. Significantly more young patients reduced alcohol consumption in comparison to the other groups. Significantly more old patients reported no 
Table 3 Characteristics by age groups

\begin{tabular}{|c|c|c|c|c|}
\hline Characteristics & Age $<\mathbf{5 0}$ years & Age $50-70$ years & Age $>70$ years & P-value \\
\hline Patients (n) & 52 & III & 37 & \\
\hline Age (years), mean $\pm S D$ & $38 \pm 8$ & $6 I \pm 5$ & $78 \pm 5$ & \\
\hline Length of disease (years), mean $\pm S D$ & $9 \pm 11$ & $12 \pm 12$ & $13 \pm 10$ & $<0.001$ \\
\hline NYHA & $\mathrm{I} .588$ & 1.66 & $\mathrm{I} .743$ & 0.33 \\
\hline BNP (pg/mL) & $\mathrm{I}, 058$ & 502 & 583 & 0.19 \\
\hline Pro-BNP (pg/mL) & 4,191 & 2,621 & 3,817 & 0.76 \\
\hline
\end{tabular}

Abbreviations: BNP, B-type natriuretic peptide; NYHA, New York Heart Association; pro-BNP, N-terminal of the prohormone brain natriuretic peptide.

changes to their sexual activity in comparison to the other groups (Figure 6).

\section{Discussion}

In our study, we analyzed the knowledge of a patient about his disease, which influences compliance with medical instructions and perception of the quality of life (QOL). These factors, although very subjective, can strongly affect a physician's cooperation with a CHF patient. CHF decreases QOL and survival prognosis similar to cancer. ${ }^{15}$ Thus, we decided to design a nonstandardized survey, instead of using already existing standardized questionnaires, in such a way that the patients could freely choose which part of the treatment and communication should be improved.

The young and the mild CHF patients tend to believe CHF to be curable, while the old and those with severe CHF were more skeptical. It is comparable to the data obtained

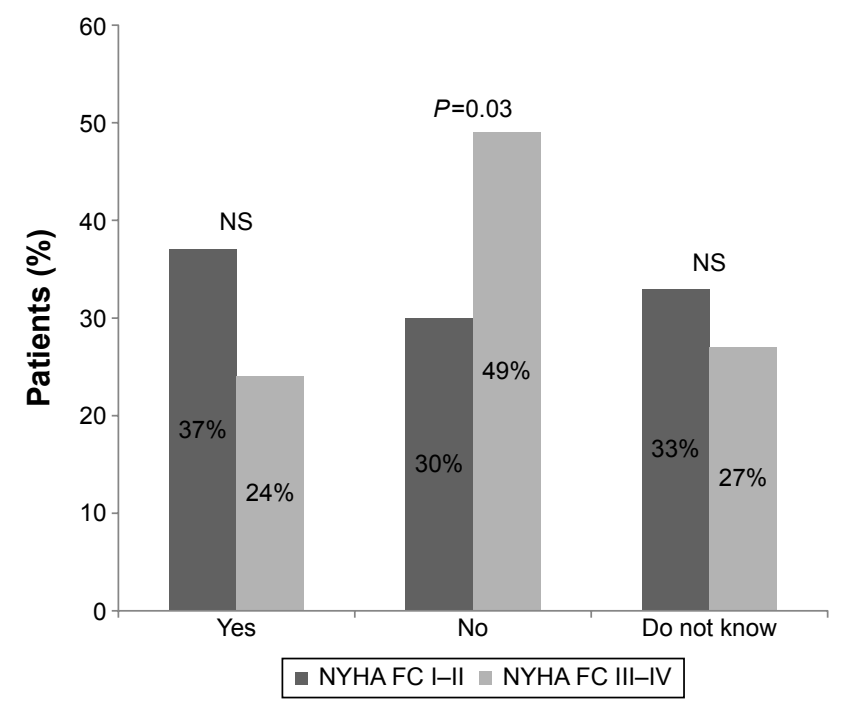

Figure I Response to question: "Do you think HF is curable?", sorted by NYHA FC group.

Abbreviations: FC, functional class; HF, heart failure; NS, not significant; NYHA, New York Heart Association. by van der Wal et al - the older patients, with frequent rehospitalizations, tended to perceive their disease more negatively. ${ }^{16}$ Surprisingly, in our study, $37 \%$ patients with I-II NYHA class and $24 \%$ patients classified as III-IV NYHA class perceived CHF as curable, in comparison with $9 \%$ among the van der Wal subjects.

In general, we observed similar QOL decrease with increasing NYHA class as Juenger et al among the Heidelberg population 14 years ago, who used the SF-36 survey. ${ }^{17}$ The same result was obtained in a study of Turkish population in a smaller group of only 35 patients. ${ }^{18}$ It seems that QOLimproving drugs still do not meet the patients' expectations. Physical symptoms like shortness of breath or chest pain were associated with severe CHF, comparable to the survey-based study of Heo et al dated 2010. ${ }^{19}$

The level of knowledge about alarming symptoms lays a shadow on the communication between doctors and

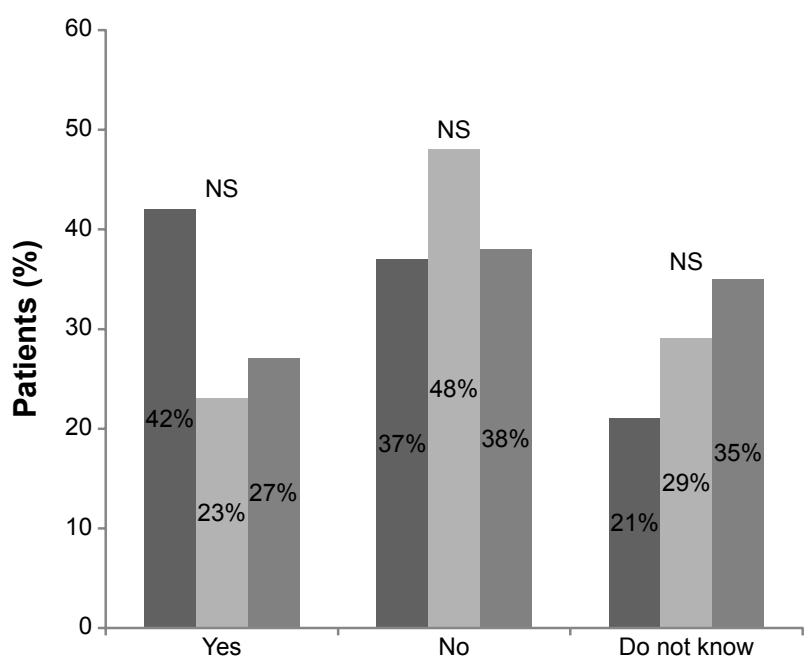

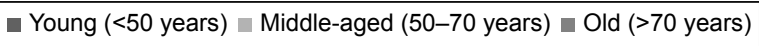

Figure 2 Response to question: "Do you think HF is curable?", sorted by age group.

Abbreviations: HF, heart failure; NS, not significant. 


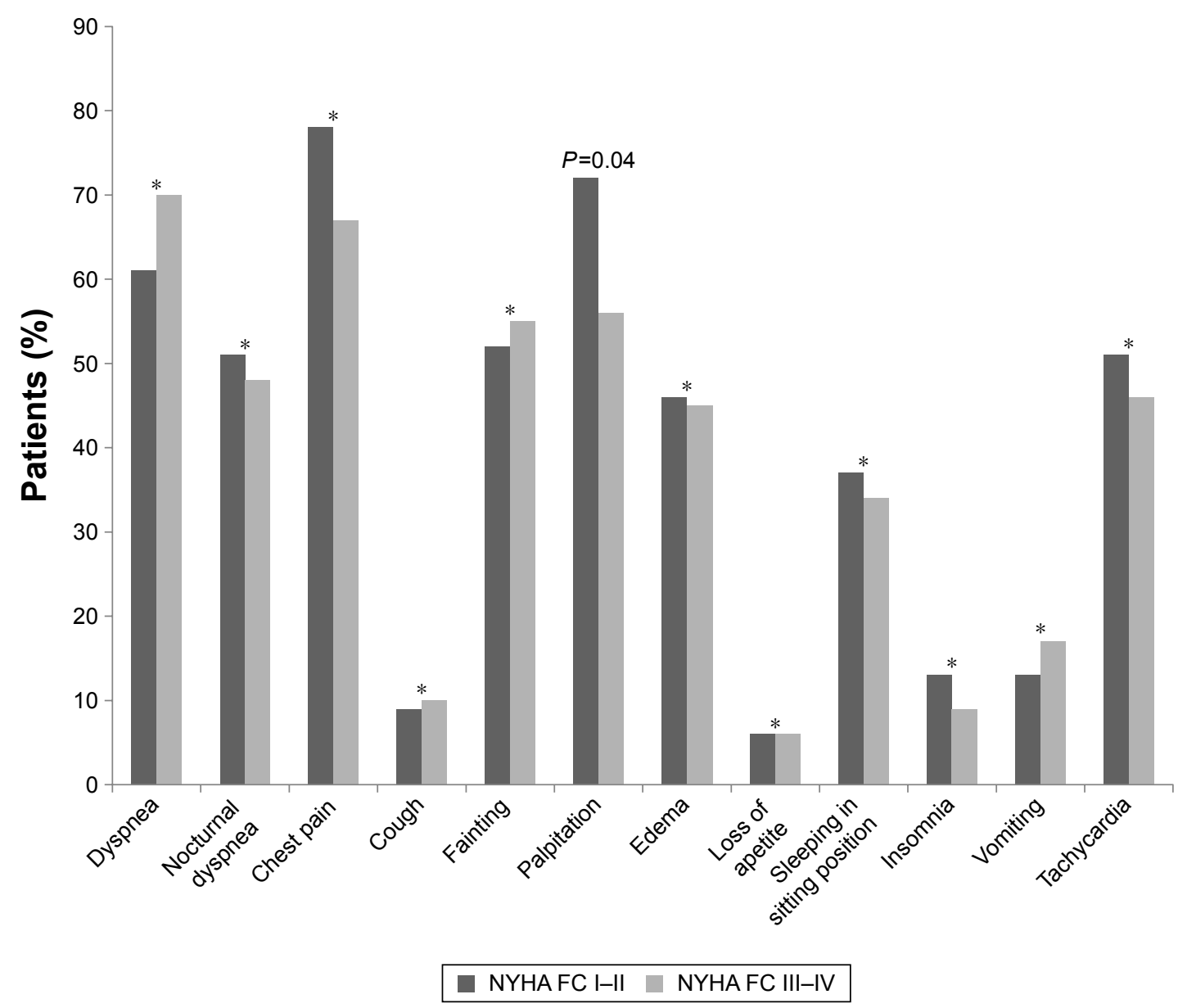

Figure 3 Positive response to question: “Do you consider this symptom alarming?", sorted by NYHA FC group.

Note: *Not significant.

Abbreviations: FC, functional class; NYHA, New York Heart Association.

patients showing either doctors as ineffective teachers, being expected to provide patients with all the necessary information, or incapable of gaining patients' trust to correct their inaccurate knowledge from other sources. In Poland, there is no other professional source of medical knowledge to educate patients, so doctors sometimes present paternal attitude regarding this matter. CHF multidisciplinary programs and informative initiatives are still novel ideas and

Table 4 Positive response to question: "Do you consider this symptom alarming?"

\begin{tabular}{|c|c|c|c|c|c|c|c|}
\hline Symptoms & Age $20-50$ years & Age $\mathbf{5 0 - 7 0}$ years & Age $>70$ years & $P$-value & NYHA FC I-II & NYHA FC III-IV & $P$-value \\
\hline Dyspnea & $63 \%(33)$ & $69 \%(77)$ & $68 \%(25)$ & 0.75 & $61 \%(4 I)$ & $70 \%(88)$ & 0.29 \\
\hline Nocturnal dyspnea & $48 \%(25)$ & $52 \%(58)$ & $43 \%(16)$ & 0.62 & $51 \%(34)$ & $48 \%(6 I)$ & 0.87 \\
\hline Chest pain & $73 \%(38)$ & $73 \%(81)$ & $62 \%(23)$ & 0.42 & $78 \%(52)$ & $67 \%(85)$ & 0.19 \\
\hline Cough & $10 \%(5)$ & $10 \%(11)$ & $11 \%(4)$ & 0.98 & $9 \%(6)$ & $10 \%(13)$ & 0.96 \\
\hline Fainting & $52 \%(27)$ & $53 \%(59)$ & $65 \%(24)$ & 0.41 & $52 \%(35)$ & $55 \%(69)$ & 0.85 \\
\hline Palpitation & $60 \%(31)$ & $66 \%(73)$ & $49 \%(18)$ & 0.18 & $72 \%(48)$ & $56 \%(70)$ & 0.04 \\
\hline Edema & $60 \%(31)$ & $44 \%(49)$ & $35 \%(13)$ & 0.06 & $46 \%(31)$ & $45 \%(57)$ & 0.99 \\
\hline Loss of appetite & $4 \%(2)$ & $6 \%(7)$ & $8 \%(3)$ & 0.69 & $6 \%(4)$ & $6 \%(8)$ & 0.83 \\
\hline Sleeping in sitting position & $48 \%(25)$ & $33 \%(37)$ & $24 \%(9)$ & 0.05 & $37 \%(25)$ & $34 \%(43)$ & 0.78 \\
\hline Insomnia & $12 \%(6)$ & $8 \%(9)$ & $14 \%(5)$ & 0.58 & $13 \%(9)$ & $9 \%(I I)$ & 0.44 \\
\hline Vomiting & $12 \%(6)$ & $18 \%(20)$ & $16 \%(6)$ & 0.57 & $13 \%(9)$ & $17 \%(22)$ & 0.60 \\
\hline Tachycardia & $42 \%(22)$ & $53 \%(59)$ & $70 \%(26)$ & 0.03 & $51 \%(34)$ & $46 \%(58)$ & 0.64 \\
\hline
\end{tabular}

Notes: Data shown as percentage (n). Data shown in bold indicate significant associations with palpitations and NYHA functional class and tachycardia and age of patients, respectively.

Abbreviations: FC, functional class; NYHA, New York Heart Association. 


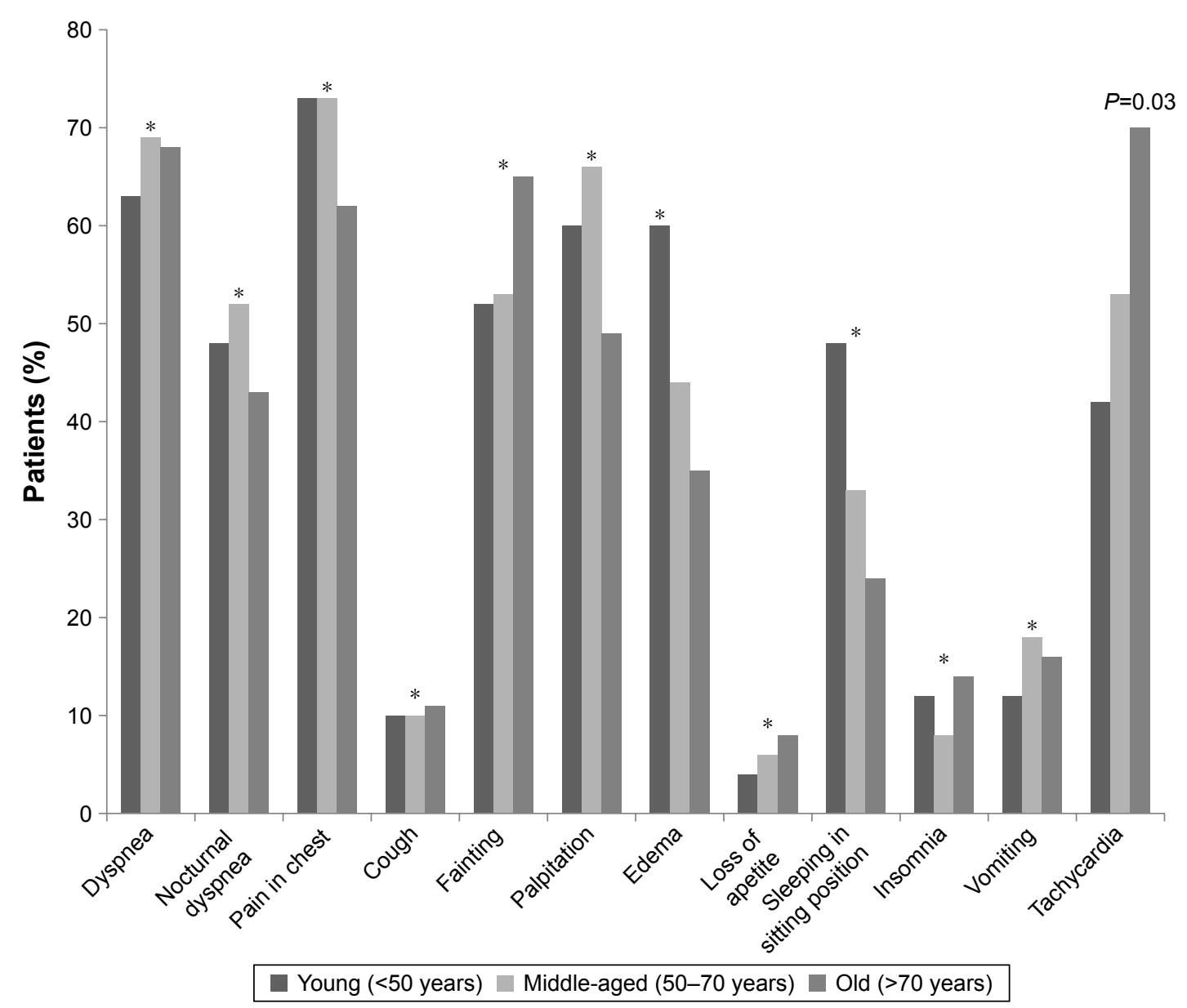

Figure 4 Positive response to question: “Do you consider this symptom alarming?", sorted by age group. Note: *Not significant.

not very common in Poland. Nurses specialized in CHF could very well fill this gap. The patients in general know which symptoms are the most alarming, but the majority do not recognize particular symptoms as CHF symptoms or do not link them with one another, that is, sleeping in sitting position with dyspnea or insomnia. It leads to the assumption that a presenting patient will report only the most urgent symptoms of his disease. It is rather because

Table 5 Lifestyle changes among patients

\begin{tabular}{|c|c|c|c|c|c|c|c|}
\hline Lifestyle changes & NYHA FC I-II & NYHA FC III-IV & $P$-value & Age $20-50$ years & Age $50-70$ years & Age $>70$ years & $P$-value \\
\hline Diet change & $37 \%(25)$ & $4 I \%(5 I)$ & 0.78 & $40 \%(2 I)$ & $43 \%(48)$ & $32 \%(12)$ & 0.51 \\
\hline Regular exercise & $33 \%(22)$ & $16 \%(20)$ & 0.01 & $25 \%(13)$ & $23 \%(25)$ & $11 \%(4)$ & 0.23 \\
\hline Less exercise & $33 \%(22)$ & $55 \%(69)$ & $<0.01$ & $50 \%(26)$ & $48 \%(53)$ & $41 \%(15)$ & 0.66 \\
\hline \multicolumn{8}{|l|}{ BMI } \\
\hline No change & $48 \%(32)$ & $48 \%(6 I)$ & 0.77 & $58 \%(30)$ & $41 \%(45)$ & $57 \%(2 I)$ & 0.04 \\
\hline Lower & $45 \%(30)$ & $41 \%(52)$ & 0.77 & $27 \%(14)$ & $50 \%(56)$ & $38 \%(14)$ & 0.04 \\
\hline Higher & $7 \%(5)$ & $10 \%(13)$ & 0.77 & $15 \%(8)$ & $9 \%(10)$ & $5 \%(2)$ & 0.04 \\
\hline Less alcohol & $45 \%(30)$ & $37 \%(46)$ & 0.37 & $46 \%(24)$ & $44 \%(49)$ & $16 \%(6)$ & 0.02 \\
\hline Less smoking & $39 \%(26)$ & $43 \%(54)$ & 0.7 & $44 \%(23)$ & $50 \%(56)$ & $16 \%(6)$ & $<0.01$ \\
\hline \multicolumn{8}{|l|}{ Sexual activity } \\
\hline No change & $60 \%(40)$ & $52 \%(66)$ & $<0.01$ & $67 \%(35)$ & $41 \%(46)$ & $78 \%(23)$ & $<0.01$ \\
\hline Lower & $31 \%(2 I)$ & $48 \%(60)$ & $<0.01$ & $31 \%(16)$ & $55 \%(6 I)$ & $19 \%(7)$ & $<0.01$ \\
\hline Higher & $9 \%(6)$ & $0 \%(0)$ & $<0.01$ & $2 \%(1)$ & $4 \%(4)$ & $3 \%(1)$ & $<0.01$ \\
\hline
\end{tabular}

Notes: Data shown as percentage (n). Data shown in bold indicated lifestyle changes that were significantly associated with either NYHA functional class or age. Abbreviations: BMI, body mass index; FC, functional class; NYHA, New York Heart Association. 


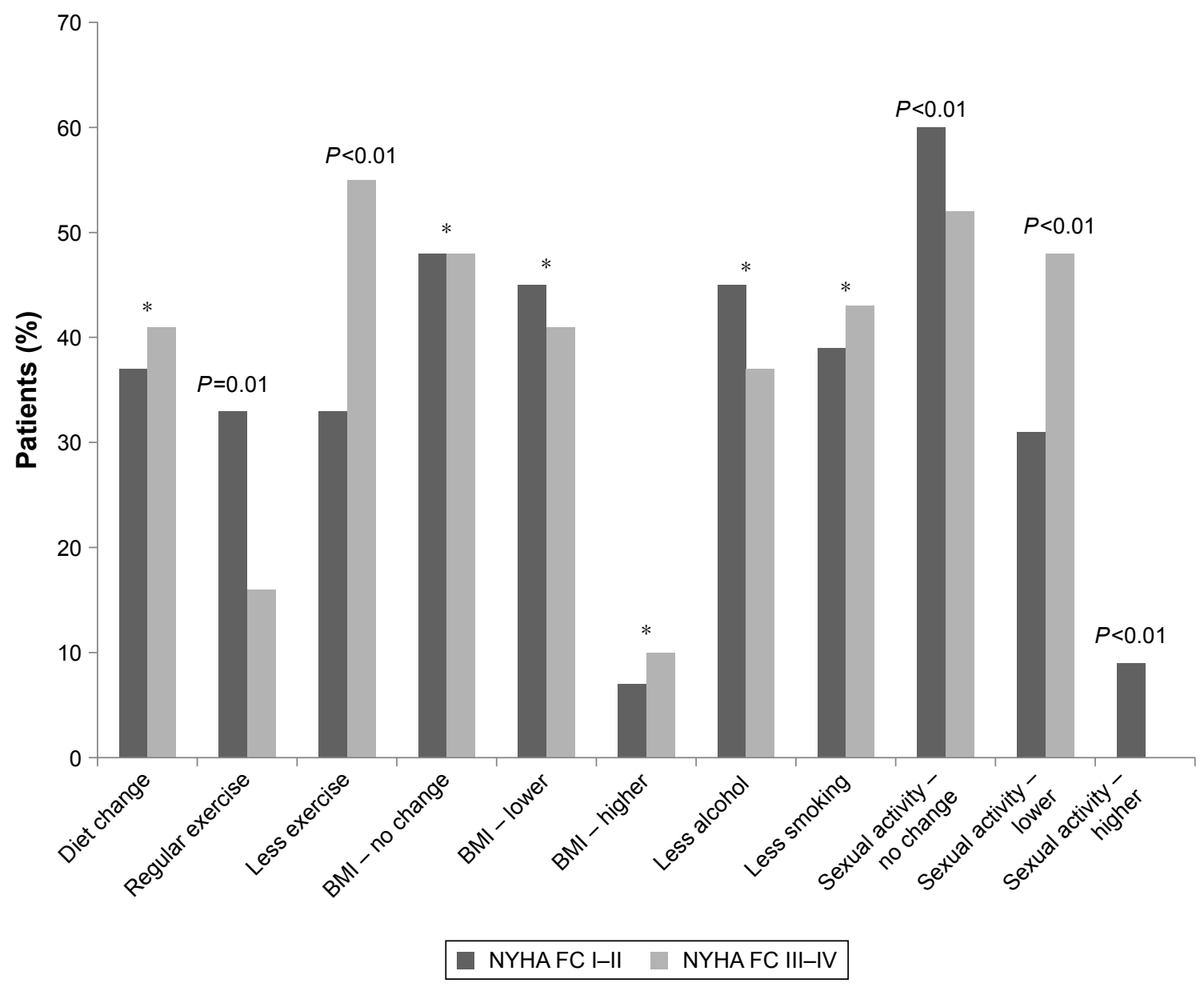

Figure $\mathbf{5}$ Lifestyle changes among patients, sorted by NYHA FC I-II and NYHA FC III-IV.

Note: *Not significant.

Abbreviations: BMI, body mass index; FC, functional class; NYHA, New York Heart Association.

of their significance for the patient, and not because the patient was instructed about their importance by medical professionals. Perhaps specialized nurses could work as educators in lifestyle and symptoms of CHF as shown among the US population. The more educated a patient is, the fewer readmissions, as proved in a very similar population to ours. ${ }^{20}$ On discharge, it is recommended not just to provide a regular hospital discharge record, but a one-onone educational session with a medical professional seems necessary. Such attitude seems crucial especially among the elderly patients. ${ }^{21}$

It seems that the most compliant group is the middleaged, who already raised families, have a rather stable professional situation and are able to follow medical instructions. However, suffering patients generally prefer not to follow lifestyle changes, as observed in simple salt intake restrictions. ${ }^{22}$ Generally patients tend to exercise less when diagnosed with HF, some lose weight but rather as a result of the disease because of cachexia and muscle mass reduction, but their sexual activity remains normal for age. It is never enough stressed to exercise in CHF - the proper activity level of CHF patient training sessions is still researched. ${ }^{23}$ Just 3 months of regular training improves outcomes among CHF patients. ${ }^{24}$ Proper self-management in this case seems to lower readmissions rate, but it is still not supported by scientific evidence. ${ }^{25}$

\section{Conclusion}

Patients' education seems crucial in treatment of CHF. It needs to be clarified during the first medical visits that $\mathrm{CHF}$ cannot be cured. Patients should be educated about the symptoms of CHF, even though the majority indicates correct signs and symptoms as most alarming. It seems important to encourage positive lifestyle changes, like proper diet and exercise as prognosis-improving, lowering readmission rate and reducing CHF care costs. 


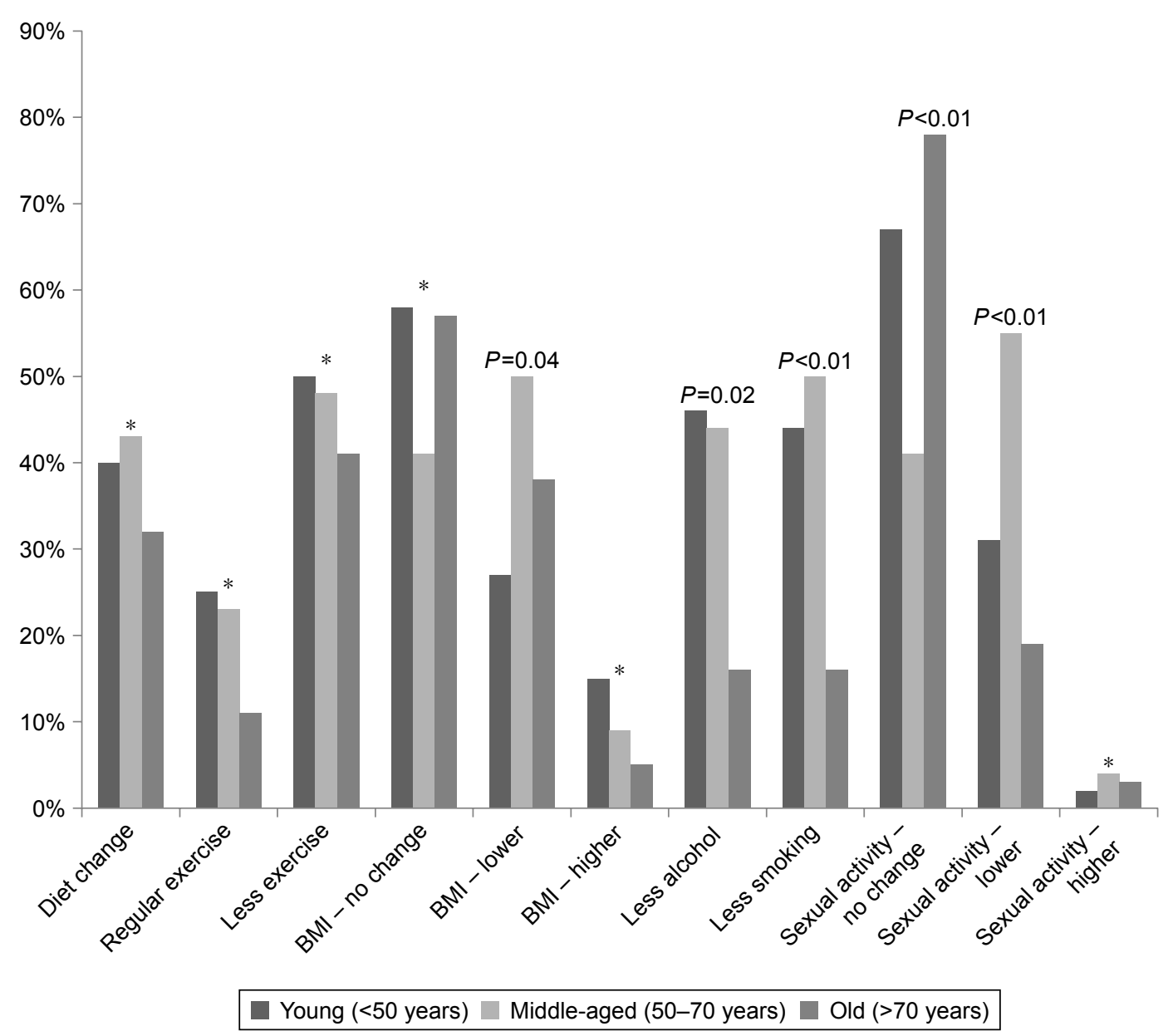

Figure 6 Lifestyle changes among patients, sorted by various age groups. Note: *Not significant.

\section{Acknowledgment}

The authors wish to thank all the patients, collaborators and institutions that contributed to conduction of this study.

\section{Disclosure}

The authors report no conflicts of interest in this work.

\section{References}

1. World Health Organization. Cardiovascular diseases (CVDs). Fact sheet $N^{\circ} 317$ September 2016. Available from: http://www.who.int/ mediacentre/factsheets/fs317/en/. Accessed October 10, 2016.

2. McMurray JJV, Stewart S. The burden of heart failure. Eur Heart J Supplements. 2002;4(Suppl D):D50-D58.

3. Lloyd-Jones DM, Larson MG, Leip EP, et al. Lifetime risk for developing congestive heart failure: the Framingham Heart Study. Circulation. 2002;106(24):3068-3072.

4. McMurray JJ, Stewart S. Epidemiology, aetiology, and prognosis of heart failure. Heart. 2000;83(5):596-602.

5. Remme WJ, McMurray JJ, Rauch B, et al. Public awareness of heart failure in Europe: first results from shape. Eur Heart J. 2005;26(22): 2413-2421.

6. Rogers AE, Addington-Hall JM, Abery AJ, et al. Knowledge and communication difficulties for patients with chronic heart failure: qualitative study. BMJ. 2000;321(7261):605-607.
7. van der Wal MH, Jaarsma T, Moser DK, Veeger NJ, van Gilst WH, van Veldhuisen DJ. Compliance in heart failure patients: the importance of knowledge and beliefs. Eur Heart J. 2006;27(4):434-440.

8. Rogers A, Addington-Hall JM, McCoy AS, et al. A qualitative study of chronic heart failure patients' understanding of their symptoms and drug therapy. Eur J Heart Fail. 2002;4(3):283-287.

9. Klindtworth K, Oster P, Hager K, Krause O, Bleidorn J, Schneider N. Living with and dying from advanced heart failure: understanding the needs of older patients at the end of life. BMC Geriatr. 2015; 15:125.

10. Gravely-Witte S, Jurgens CY, Tamim H, Grace SL. Length of delay in seeking medical care by patients with heart failure symptoms and the role of symptom-related factors: a narrative review. Eur J Heart Fail. 2010; 12(10):1122-1129.

11. Lainscak M, Blue L, Clark AL, et al. Self-care management of heart failure: practical recommendations from the patient care committee of the heart failure association of the European Society of Cardiology. Eur J Heart Fail. 2011;13(2):115-126.

12. Lee CS, Tkacs NC, Riegel B. The influence of heart failure self-care on health outcomes: hypothetical cardioprotective mechanisms. J Cardiovasc Nurs. 2009;24(3):179-187; quiz 188-179.

13. Heo S, Lennie TA, Moser DK, Okoli C. Heart failure patients' perceptions on nutrition and dietary adherence. Eur J Cardiovasc Nurs. 2009;8(5):323-328.

14. van der Wal MH, van Veldhuisen DJ, Veeger NJ, Rutten FH, Jaarsma T. Compliance with non-pharmacological recommendations and outcome in heart failure patients. Eur Heart J. 2010;31(12):1486-1493. 
15. Stewart S, MacIntyre K, Hole DJ, Capewell S, McMurray JJ. More 'malignant' than cancer? Five-year survival following a first admission for heart failure. Eur J Heart Fail. 2001;3(3):315-322.

16. van der Wal MH, Jaarsma T, van Veldhuisen DJ. Non-compliance in patients with heart failure; how can we manage it? Eur J Heart Fail. 2005; 7(1):5-17.

17. Juenger J, Schellberg D, Kraemer S, et al. Health related quality of life in patients with congestive heart failure: comparison with other chronic diseases and relation to functional variables. Heart. 2002;87(3): 235-241.

18. Karapolat H, Durmaz B, Nalbantgil S, Durmaz I. [Quality of life and functional status in congestive heart failure]. Anadolu Kardiyol Derg. 2006;6(4):327-332. Turkish.

19. Heo S, Lennie TA, Okoli C, Moser DK. Quality of life in patients with heart failure: ask the patients. Heart Lung. 2009;38(2):100-108.

20. Koelling TM, Johnson ML, Cody RJ, Aaronson KD. Discharge education improves clinical outcomes in patients with chronic heart failure. Circulation. 2005;111(2):179-185.
21. Rich MW, Vinson JM, Sperry JC, et al. Prevention of readmission in elderly patients with congestive heart failure: results of a prospective, randomized pilot study. J Gen Intern Med. 1993;8(11):585-590.

22. Dolansky MA, Schaefer JT, Hawkins MA, et al. The association between cognitive function and objective adherence to dietary sodium guidelines in patients with heart failure. Patient Prefer Adherence. 2016;10:233-241.

23. Ulbrich AZ, Angarten VG, Netto AS, et al. Comparative effects of high intensity interval training versus moderate intensity continuous training on quality of life in patients with heartfailure: study protocol for a randomized controlled trial. Clin Trials Regul Sci Cardiol. 2016;13:21-28.

24. Safiyari-Hafizi H, Taunton J, Ignaszewski A, Warburton DE. The health benefits of a 12-week home-based interval training cardiac rehabilitation program in patients with heart failure. Can J Cardiol. 2016; 32(4):561-567.

25. Young L, Hertzog M, Barnason S. Effects of a home-based activation intervention on self-management adherence and readmission in rural heart failure patients: the PATCH randomized controlled trial. BMC Cardiovasc Disord. 2016;16(1):176.

\section{Publish your work in this journal}

Patient Preference and Adherence is an international, peer-reviewed, open access journal that focuses on the growing importance of patient preference and adherence throughout the therapeutic continuum. Patient satisfaction, acceptability, quality of life, compliance, persistence and their role in developing new therapeutic modalities and compounds to optimize clinical outcomes for existing disease states are major areas of interest for the journal. This journal has been accepted for indexing on PubMed Central. The manuscript management system is completely online and includes a very quick and fair peer-review system, which is all easy to use. Visit http://www. dovepress.com/testimonials.php to read real quotes from published authors.

Submit your manuscript here: http://www.dovepress.com/patient-preference-and-adherence-journal 